\title{
ERRATUM
}

doi:10.2489/jswc.2021.10131

\section{Erratum for Xiao et al., Crop type drives soil bacterial community and functional structure on the Loess Plateau terraces of China}

Volume 76(4), page 349: Lines 1-8 in the Author Information box should read as follows: "Li Xiao is a doctoral student in the College of Natural Resources and Environment, Northwest A\&F University, and China University of Mining and Technology in Beijing, China. Yimei Huang (corresponding author) is a professor of eco-environmental engineering in the Key Laboratory of Plant Nutrition and Agrienvironment in Northwest China, College of Natural Resources and Environment, Northwest A\&F University, Yangling, China."

\section{Reference}

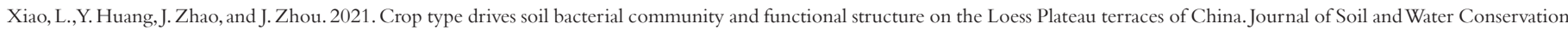
76(4):349-358. https://doi.org/10.2489/jswc.2021.00131. 